LA-UR -95-2076

TITLE: NUMERICAL SIMULATIONS OF GLASS IMPACTS USING SMOOTH PARTICLE HYDRODYNAMICS

AUTHOR(S): DAVID A. MANDELL, XHM

CHARLES A. WINGATE, XHM

SUBMITED TO: $\quad 1995$ APS TOPICAL CONFERENCE SHOCK COMPRESSION OF CONDENSED MATTER SEATTLE, WASHINGTON

AUGUST 13-18, 1995 


\section{DISCLAIMER}

Portions of this document may be illegible in electronic image products. Images are produced from the best available original document. 


\title{
NUMERICAL SIMULATIONS OF GLASS IMPACTS USING SMOOTH PARTICLE HYDRODYNAMICS
}

\author{
David A. Mandell and Charles A. Wingate \\ Los Alamos National Laboratory, Los Alamos, New Mexico 87545
}

As part of a program to develop advanced hydrocode design tools, we have implemented a brittle fracture model for glass into the SPHINX smooth particle hydrodynamics code. We have evaluated this model and the code by predicting data from one-dimensional flyer plate impacts into glass. Since fractured glass properties, which are needed in the model, are not available, we did sensitivity studies of these properties, as well as sensitivity studies to determine the number of particles needed in the calculations. The numerical results are in good agreement with the data.

\section{INTRODUCTION}

In the current work we use the SPHINX smooth particle hydrodynamics code $(1,2)$ to predict data from one-dimensional experiments in which an aluminum flyer plate impacted a glass target $(3,4)$.

Smooth Particle Hydrodynamics (SPH) is a relatively new technique for doing hydrodynamics calculations. It is a gridless, Lagrangian method in which fluid elements are represented by mass points that move according to the fluid equations of motion. Each particle carries local values of density, temperature, pressure, and other fluid parameters. Interpolation is used to find values of physical quantities between the particles.

The key feature of SPH is that it is gridless and thus does not have the mesh tangling problems of typical Lagrangian codes. Since SPH is Lagrangian, it does not have the problems with advection that typical Eulerian codes have. Also SPH only needs particles where material exits and thus does not have to zone up huge volumes of space.

The glass model developed by Cagnoux (5), and extended by Glenn and his co-workers (6) was implemented into SPHINX. This model consists of an ordinary differential equation for the glass damage, and a prescription for the damaged glass strength properties and an equation of state. The model is discussed below.

\section{DAMAGE MODEL}

A scalar damage variable, $D$, is calculated from the following equation

$$
\frac{d D}{d t}=\frac{\tau}{B(1-D)^{b \tau}}
$$

where $\tau$ is the maximum principal tensile stress, and $B$ and $b$ are material constants. The damage is zero for intact glass and one for fully damaged glass. Damage is accumulated only if $\tau$ is greater than a threshold value, $\tau_{\mathrm{o}}$. The values of $B$ and $b$ given by Cagnoux (5) were used in the calculations: $\mathrm{B}=7.010^{-5} \mathrm{kbar}$ seconds and $b=0.7 \mathrm{kbar}^{-1}$.

Once the damage is calculated, it is important to degrade the glass material strength and equation of state (EOS) in an appropriate manner. A number of methods have been used, but in the Cagnoux-Glenn model, the bulk modulus, $\mathrm{K}$; shear modulus, $\mathrm{G}$; and yield strength, $\mathrm{Y}$, are calculated as linear functions between the intact and fractured values

$$
f=f_{o}(1-D)+f_{o} f_{R} D
$$


where $f$ is $\mathrm{K}, \mathrm{G}$, or $\mathrm{Y}$. The subscript o refers to intact glass properties and the subscript $R$ refers to the ratio of the fractured glass property to the intact glass property. The EOS is

$$
\frac{d p}{d v}=-K v,
$$

where $p$ is the pressure and $v$ is the glass specific volume. It should be noted that once damage starts to accumulate, the slope of the EOS equation, $\mathrm{K}$, changes, resulting in increased glass pressure. This provides the dilatation (bulking) seen in experiments. A schematic of the glass EOS is shown in Fig. 1. The energy term added to the pressure EOS equation was not used in our work (6).

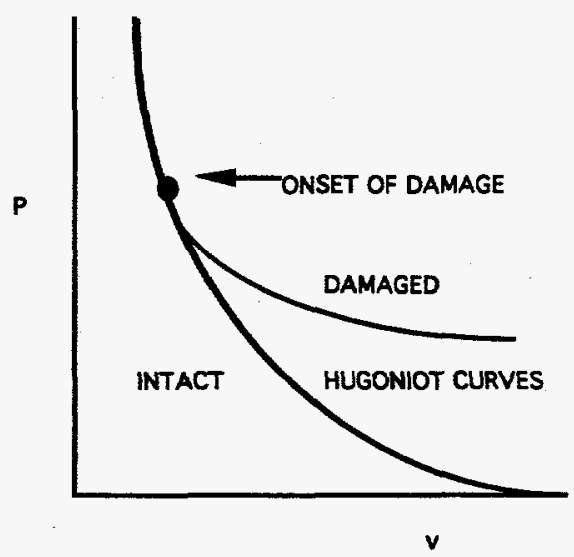

Figure 1. Intact and fractured glass pressure.

\section{NUMERICAL SIMULATIONS}

Four aluminosilicate glass flyer plate impact experiments were conducted at the Sandia National Laboratories $(3,4)$. In two experiments the 6061-T6 aluminum flyer plates had a velocity of approximately $0.96 \mathrm{~km} / \mathrm{sec}$, and in the other two experiments the velocity was about $0.45 \mathrm{~km} / \mathrm{sec}$. In each set of experiments, one experiment was conducted with a roughened glass surface and the other with a smooth surface.
Hydrocodes cannot predict the effect of the surface, so we predicted the experiments with smooth glass surfaces. A schematic of the geometry is shown in Fig. 2.

\section{ALUMINIUM FLYER PLATE}
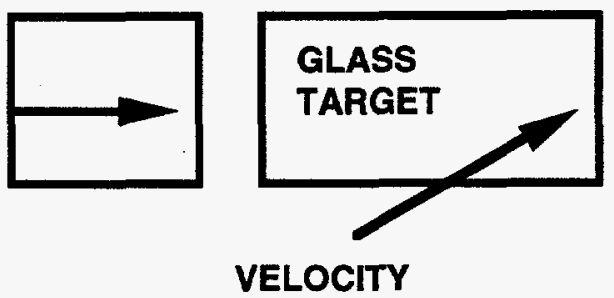

Figure 2. Schematic for the 1-D Glass Flyer Plate Predictions.

The aluminum and glass material properties used in the calculations are given in Tables 1 and 2, respectively.

Table 1.6061-T6 Aluminum Properties.

\begin{tabular}{|l|l|}
\hline VARIABLE & VALUE \\
\hline & \\
\hline Density $\left(\mathrm{gm} / \mathrm{cm}^{3}\right)$ & 2.7128445 \\
\hline Sound Speed (cm/microsecond) & 0.538 \\
\hline EOS Slope & 1.55 \\
\hline Shear Modulus (Kbar) & 265.0 \\
\hline Yield Stress (Kbar) & 2.75 \\
\hline
\end{tabular}

The experiment at the higher velocity apparently had a sufficiently large compressive stress that the glass spall strength, $\tau_{0}$, went to zero (3). For the two lower velocity experiments, spall strengths of 34.9 and 33.5 kbar were reported (4). The SPHINX predictions therefore used a spall strength of zero for the higher velocity prediction and a spall strength of 34 kbar for the lower velocity one.

The aluminum flyer plate had a length of $3.60 \mathrm{~mm}$, and the glass target had a length of $5.0 \mathrm{~mm}$. An elastic plastic material strength model was used for each material. The Grueneissen $\left(\mathrm{U}_{\mathrm{s}}-\mathrm{U}_{\mathrm{p}}\right)$ equation of state (EOS) : 
was used for the aluminum, and the Glenn EOS was used for the glass.

Table 2. Properties of Aluminosilicate Glass used in the SPHINX Calculations.

\begin{tabular}{|l|l|}
\hline VARIABLE & \begin{tabular}{l} 
EALU \\
\hline
\end{tabular} \\
\hline Density (gm/cm ${ }^{3}$ ) & 2.60 \\
\hline Shear Modulus (Kbar) & 333.0 \\
\hline Yield Stress (Kbar) & 100.0 \\
\hline Bulk Modulus (Kbar) & 417.0 \\
\hline $\begin{array}{l}\text { YR (Ratio of fractured yield stress to } \\
\text { intact yield stress) }\end{array}$ & 0.1 \\
\hline $\begin{array}{l}\text { GR (Ratio of fractured shear } \\
\text { modulus to intact shear modulus) }\end{array}$ & 0.333 \\
\hline $\begin{array}{l}\text { KR (Ratio of fractured bulk modulus } \\
\text { to intact bulk modulus) }\end{array}$ & 0.333 \\
\hline
\end{tabular}

Details of the calculation are given in a report (7).

The SPHINX predictions of the glass free surface velocity for the two glass flyer plate experiments are shown in Fig. 3. One thousand particles were used in these calculations, which are more than sufficient for a converged solution in one-dimension. Calculations were also made with 100 and 2000 particles for the lower velocity case. The calculation with 100 particles was a little different from the one with 1000 particles. The calculations with 1000 and 2000 particles were virtually identical.

\section{CONCLUSIONS}

The Cagnoux-Glenn $(5,6)$ glass fracture model has been implemented into the SPHINX smooth particle hydrodynamics code. The free surface velocities predicted by SPHINX match the data if different spall strengths are used for the higher and lower velocity experiments, Fig. 3. If the same spall strength is used for both experiments, either 0 or $34 \mathrm{kbar}$, only one of the experiments can be predicted well.

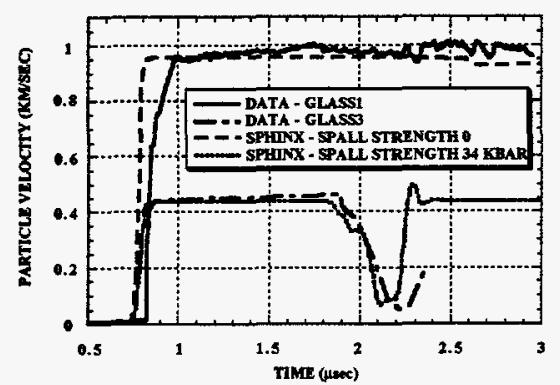

Figure. 3. Glass Free Surface Velocity.

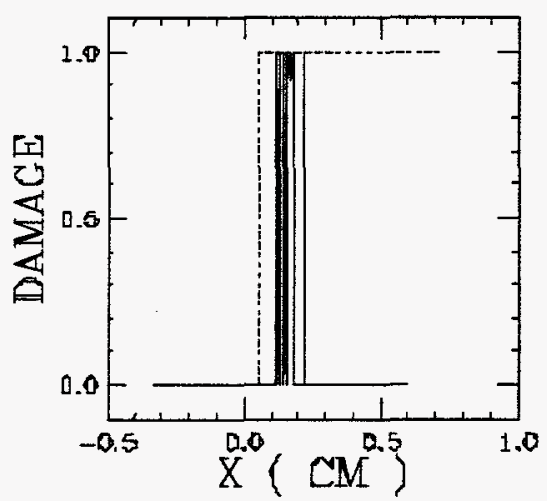

Figure 4. Glass Damage: The Low Velocity Impact is the Solid Line and the High Velocity Impact is the Dashed Line.

Figure 4 shows the damage as a function of position in the glass at the end of the calculation ( 3 microseconds) for the two simulations. It is seen from this figure that in the calculation of the high velocity experiment, the glass is completely damaged, whereas in the low velocity calculation on only a small portion of the glass is damaged. This results in the free surface results seen in Fig. 3. The characteristic spall pullback signal is calculated when specific glass cracks are predicted. In the high velocity impact the entire glass sample is fractured.

Smooth particle tensile instabilities have been seen (8), but it has been pointed out that in using a damage model that reduces the tensile stresses by $1-D$, the effect of the tensile instabilities is mitigated (9). 
A ceramic model is needed that will predict both experiments without having to input into the code different glass spall strengths.

Fractured ceramic properties are needed in all brittle damage models. These properties need to be measured.

\section{REFERENCES}

1, Stellingwerf, R. F., and Wingate, C. A., Impact Modeling With Smooth Particle Hydrodynamics, Int. J. Impact Engng, Vol 14, pp 707-718, 1993.

2. Wingate, C. A., and Stellingwerf, R. F., Los Alamos SPHINX Manual Version 5.7, Los Alamos National Laboratory Report LAUR 93-2476, January 28, 1994.

3. Raizer, G. F., Wise, J. L., Clifton, R. J., Grady, D. E., and Cox, D. E., Plate Impact Response of Ceramics and Glass, J. Appl. Phys., 75 (8), 38623869, April 15, 1994.

4. Grady, D. E., and Wise, J. L., Dynamic Properties of Ceramic Materials, Sandia National Laboratories Report SAND93-0610, September, 1993.

5. Cagnoux, J., Modele Phenomenlogique D'Ecaillage D'Un Pyrex (Phenomenological Model of Spalling of Pyrex Glass), Journal De Physique, Colloque C5, supplement au $n^{\circ} 8$ Tome 46, 1985.

6. Glenn, L. A., Moran, B., and Kusubov, A., Modeling Jet Penetration In Glass, Conference on the Application of 3-D Hydrocodes to Armor/Anti-Armor Problems, Ballistic Research Laboratory, Aberdeen Proving Grounds, MD, May 1990.

7. Mandell , David A., and Wingate, Charles A., Prediction of Material Strength and Fracture of Glass Using the SPHINX Smooth Particle Hydrodynamics Code, Los Alamos National Laboratory Report LA12830 , August, 1994. (This report is available through the Internet World Wide Web. The address is http://lib-www.lanl.gov/la-pubs/reports.htm )

8. Swegle, J. W., Attaway, S. W., Heinstein, M. W., Mello, F. J., and Hicks, D. L., An Analysis of Smooth Particle Hydrodynamics, Sandia National Laboratories Report SAND93-2513, March, 1994.
9. Benz, W., and Asphaug, E., Impact Simulations with Fracture. I. Methods and Tests, ICARUS, 107, 98-116, 1994.

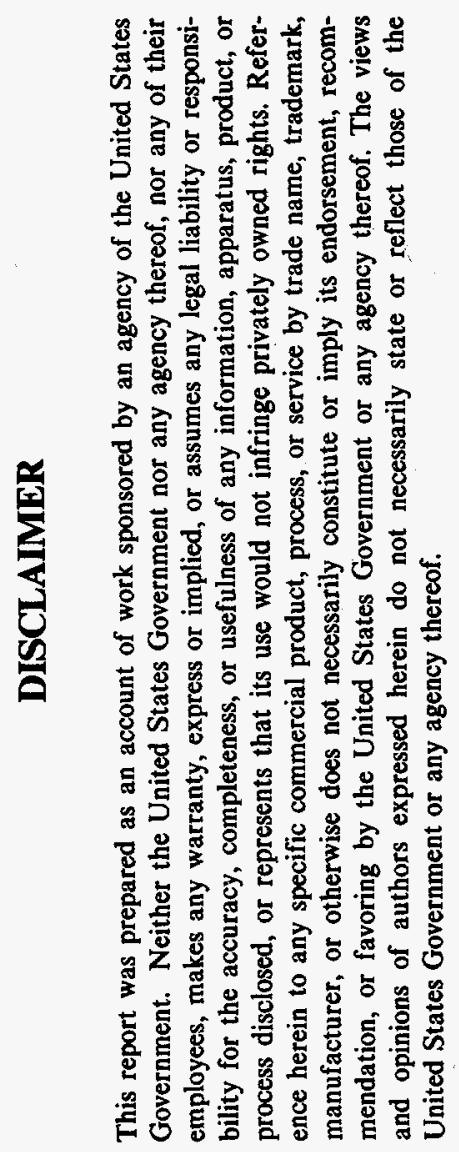

